\title{
STROKE IN NEWBORNS, INFANTS AND SMALL CHILDREN: CLINICAL ASPECTS
}

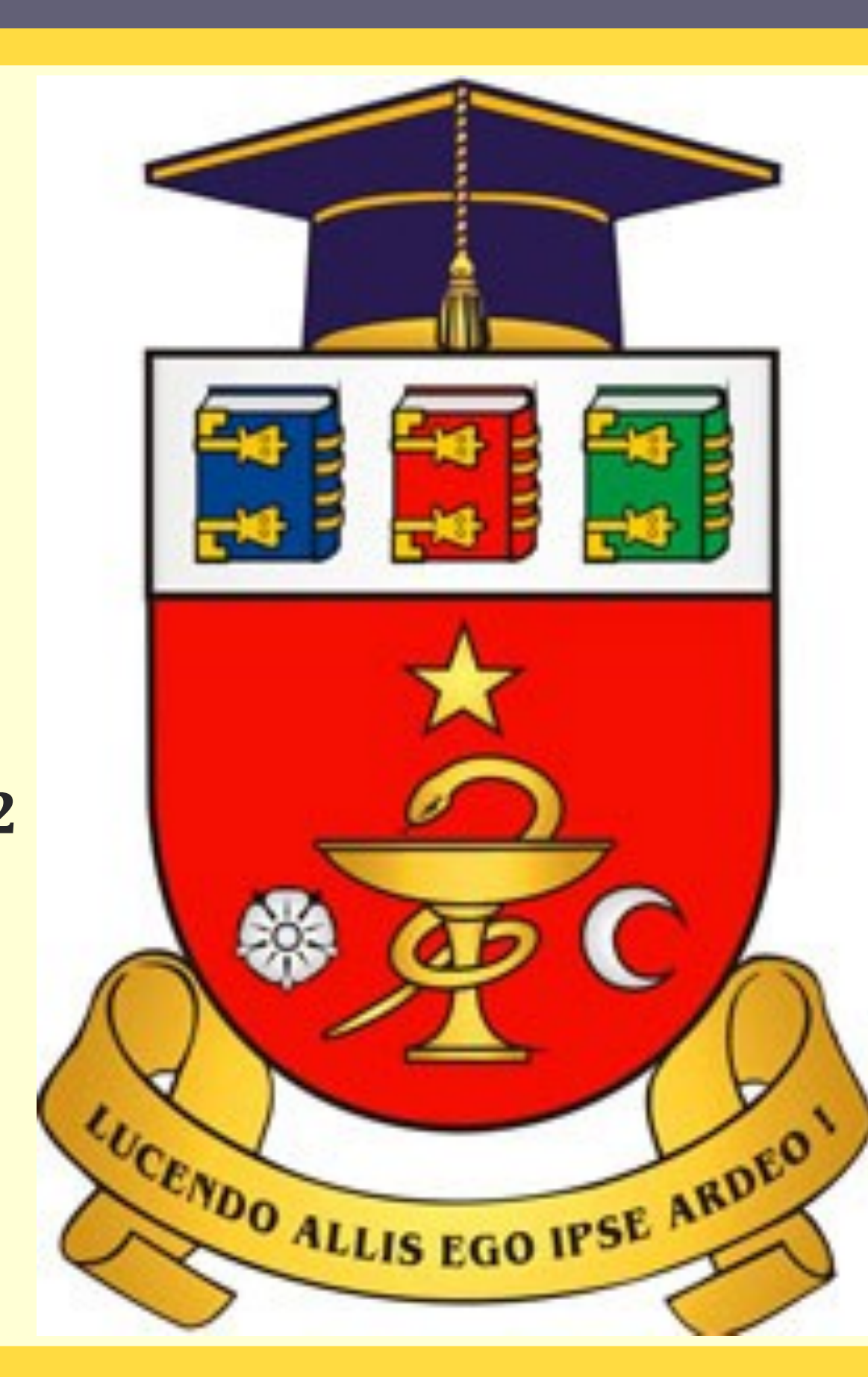

\section{Introduction}

Stroke in children is much less prevalent than in adults and is manifested with nonspecific clinical symptoms. The aim of this study was to analyze the clinical symptoms of stroke in children depending on age.

\section{Material and methods}

The stady included a group of 216 children with stroke, aged from birth to 3 years, admitted in the pediatric neurology departments. The clinical symptoms were evaluated through statistical analysis using Statistica 7.0 (Statsoft Inc) Programme.

\section{Results}

Statistical analysis allows modeling of suggestive symptoms of stroke in children depending on their age. In newborn these are: seizures $(p=0,000)$, non-focal neurological signs $(p=0,002)$, altered state of consciousness $(p=0,006)$, generalized motor abnormalities $(\mathrm{p}=0,004)$. In children from 28 days to one year of life these are: seizures $(p=0,006)$, hemiparesis $(p=0,000)$, decreased ability to squeeze the fist $(p=0,004)$, consciousness disorders $(p=0,003)$. In children from 1 to 3 years, these are: hemiparesis $(p=0,003)$, seizures $(p=0,000)$, sensory disorders $(p=0,004)$, focal movement disorders $(p=0,002)$. Brain magnetic resonance imaging data in newborn demonstrated that the most affected sites are the left hemisphere $(67,8 \%)$, anterior and middle cerebral arteries $(63,9 \%)$; multifocal lesions are in $33,2 \%$ of cases. In children from 1 to 3 years the middle cerebral artery is affected in 55,6\% and the left hemisphere in $78 \%$ of cases.

\section{Conclusions}

Diagnosis of stroke in children can often be delayed since the clinical symptoms are subtle and nonspecific, often being misdiagnosed. Logistic regression method allows establishing suggestive stroke symptoms, attributed to the category of age, which can help substantially improving the diagnosis.

\section{References}

\begin{tabular}{|c|c|c|c|c|}
\hline \multicolumn{5}{|c|}{ Newborn $(n=202)$} \\
\hline Symptoms & Abs. & P士ES (\%) & $95_{\mathrm{CI}}$ & $\mathbf{P}$ \\
\hline Seizures & 158 & 78,2 & $75,3-81,1$ & 0,001 \\
\hline Non-focal neurological signs & 136 & 67,3 & $64,0-70,6$ & 0,001 \\
\hline $\begin{array}{ll}\begin{array}{l}\text { Altered state } \\
\text { consciousness }\end{array} & \text { of } \\
\end{array}$ & 147 & 72,8 & $69,67-75,93$ & 0,001 \\
\hline $\begin{array}{l}\text { Generalized motor } \\
\text { abnormalities }\end{array}$ & 128 & 63,4 & $60,01-66,79$ & 0,001 \\
\hline \multicolumn{5}{|c|}{ Children aged from 28 days to one year of life $(n=5)$} \\
\hline Hemiparesis & 5 & 35,7 & $22,89-48,51$ & 0,05 \\
\hline $\begin{array}{l}\text { Decreased ability to squeeze } \\
\text { the fist }\end{array}$ & $\overline{3}$ & 60 & $38,09-81,91$ & 0,001 \\
\hline Seizures & 4 & 80 & $62,11-97,89$ & 0,001 \\
\hline Consciousness disorders & $\overline{3}$ & 60 & $38,09-81,91$ & 0,001 \\
\hline \multicolumn{5}{|c|}{$\begin{array}{r}\text { Children aged from } 1 \text { to } 3 \text { years }(n=9) \\
\end{array}$} \\
\hline Hemiparesis & 5 & 55,6 & $39,04-72,16$ & 0,01 \\
\hline Focal movement disorders & 6 & 66,7 & $50,99-82,41$ & 0,001 \\
\hline \begin{tabular}{|l} 
Sensory disorders \\
\end{tabular} & 7 & 77,8 & $63,94-91,66$ & $\overline{0,001}$ \\
\hline Seizures & 7 & 77,8 & $63,94-91,66$ & 0,001 \\
\hline
\end{tabular}

Symptoms of stroke in newborn $(n=202)$

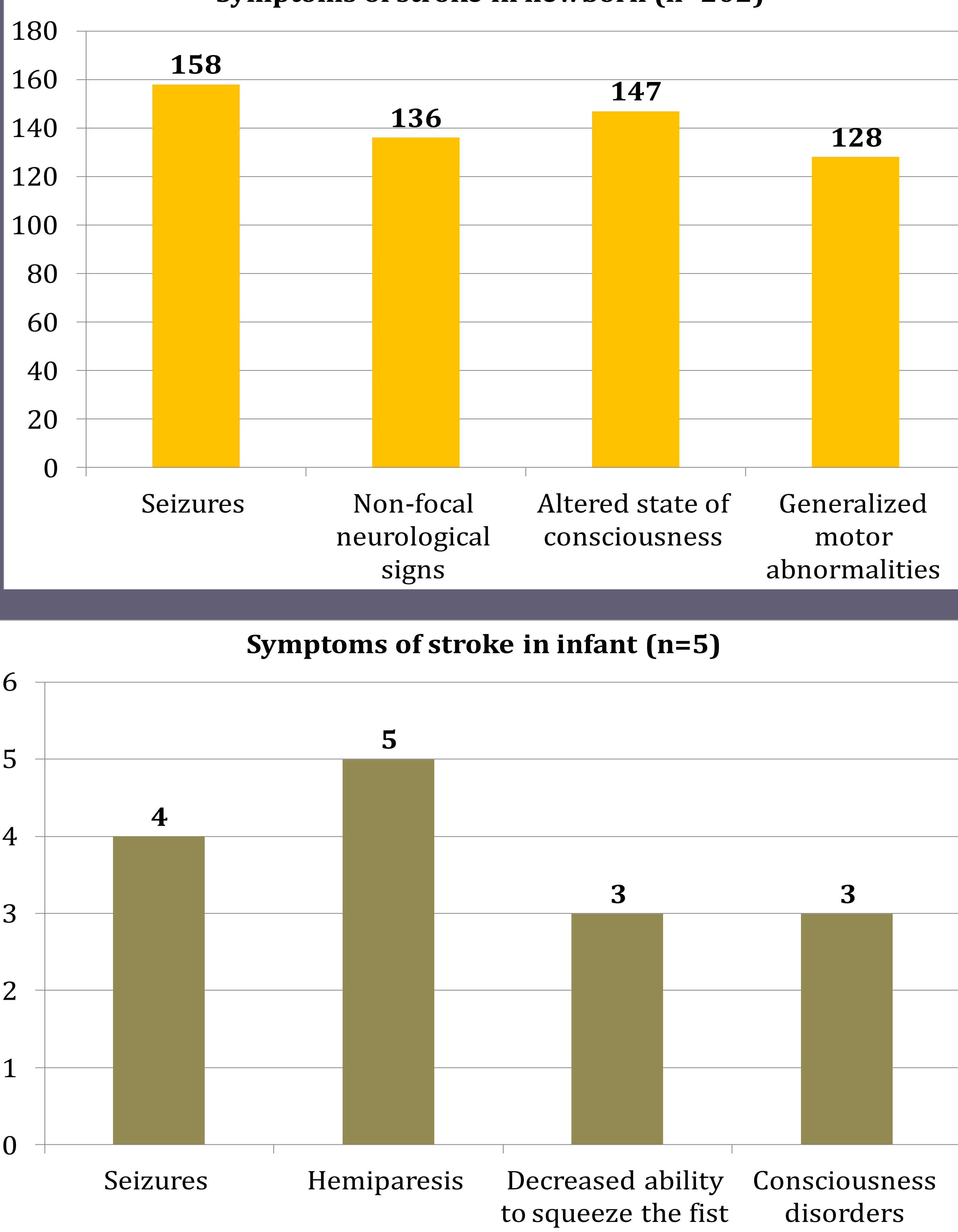

Symptoms of stroke in children from 1 to 3 years $(n=9)$

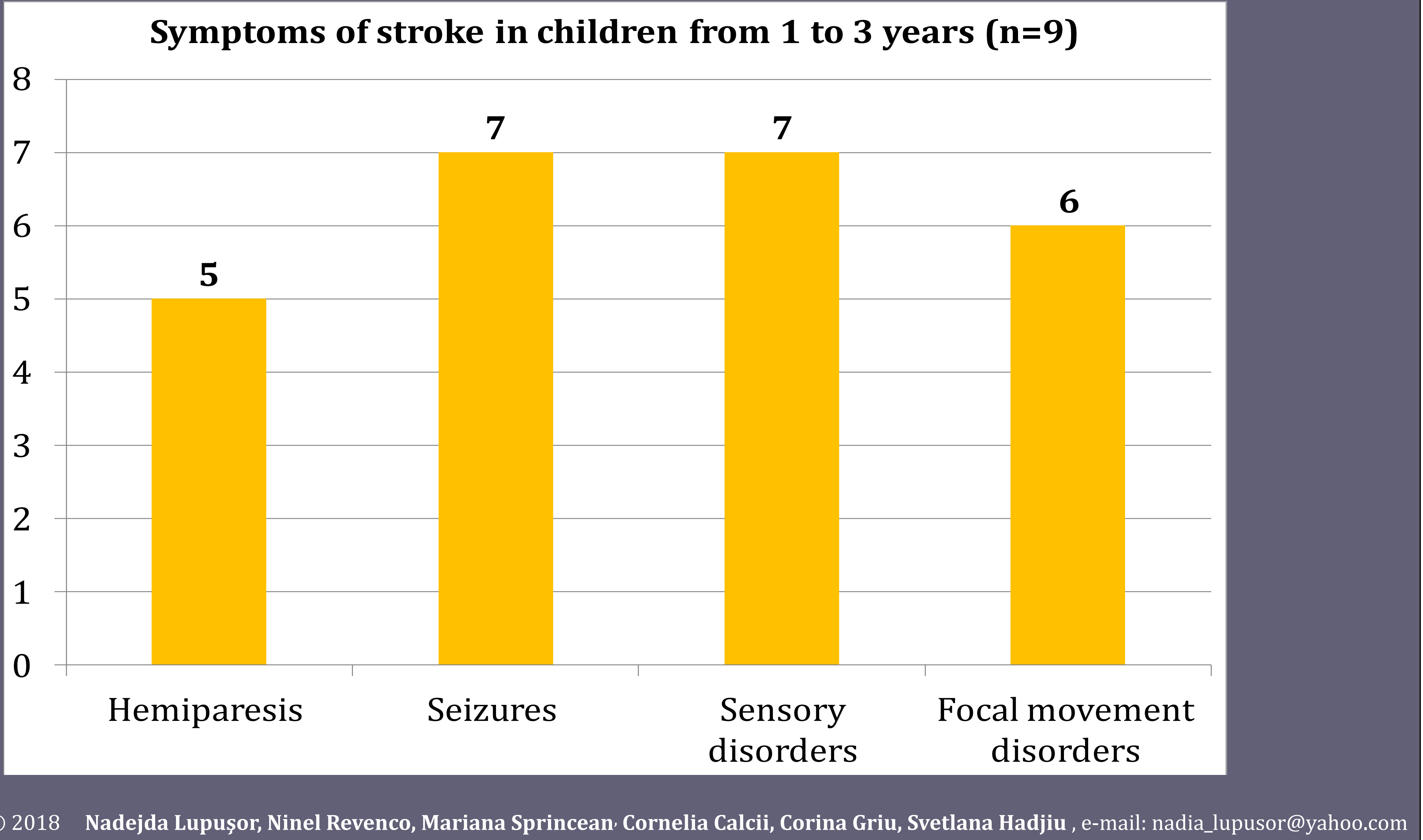

